\title{
Springtime Monitoring of Passive Cool Roofs in Subtropical Climate
}

\author{
Carla Fernanda Barbosa Teixeira ${ }^{1}$ and Lucila Chebel Labaki ${ }^{2}$ \\ 1. LACAF (Laboratory of Environmental Comfort and Applied Physics), University of Campinas, São Paulo 49170-000, Brazil \\ 2. DAC (Department of Architecture and Construction), University of Campinas, São Paulo 13083-852, Brazil
}

\begin{abstract}
Passive strategies for acclimatization of buildings have been studied by several authors in many countries, especially the evaporative and radiant cooling techniques. Fiber cement tiles are very common in popular constructions due to their low cost. However, they have over twice of the value thermal transmittance indicated to this bioclimatic zone according to Brazilian guidelines. The objective is to present an alternative to reduce high temperatures on fiber cement tiles. In this paper, the monitoring of passive cooling of roofing during the spring season in a city with subtropical climate is described. Single and combined reflective and evaporative cooling systems were studied in different environmental conditions. Internal surface temperatures of tiles were monitored together with weather variables. Results show a decrease of about $6{ }^{\circ} \mathrm{C}, 9{ }^{\circ} \mathrm{C}, 10^{\circ} \mathrm{C}$ and $11{ }^{\circ} \mathrm{C}$ as compared to the original tiles according to environment conditions and the combined passive cooling techniques. These results allow for the conclusion that the use of passive cooling techniques opens up new possibilities to attenuate the internal surface temperatures of tiles and to consequently decrease the roofing solar heat gain into buildings, thus, providing less air cooling energy consumption.
\end{abstract}

Key words: Passive cooling roofing, white coating, water spraying, subtropical climate.

\section{Introduction}

What do tropical and subtropical areas have in common? Sun, powerful and abundant, that is present almost every day of the year. This means light, food, energy and heat. The sun is directly responsible for the feeding processes of plants and microorganism, auxiliary in fixing vitamins and minerals in our bodies, besides keeping the earth warm. It is impossible, nowadays, to imagine the modern life in cities without the benefits of solar energy for batteries, water heating, buildings, cars and so many other uses.

On the other hand, advanced technologies are applied in constructions and cities for achieving a comfortable and modern life. In the meantime, between the tropical lines, many countries have imported architectural models without local and climatic evaluation of their applicability. Many factors

Corresponding author: Carla Fernanda Barbosa Teixeira, Ph.D., research fields: passive cooling roofing, bioclimatic architecture, reflective and evaporative cooling. E-mail: cafbt@yahoo.com.br. are responsible for this disregard: international and global trade, absence of building legislations and standards in many countries, lack of technical knowledge among builders, engineers, architects and other construction professionals. Unfortunately in most countries, there is no appropriate regulation to minimize solar effects on energy consumption in buildings and cities. And constructions as well as building elements have become lighter and consequently more vulnerable to heat, so that more energy is necessary for obtaining thermal comfort for people.

This scenery was very common in several countries since the second half of last century. A lot of glass facades, thin components and hermetic envelopes became present in many buildings in urban locations. This is the case of Brazil, where the energy demands are increasingly required to supply the consumption for built environment acclimatization. In a more recent context, it can be observed that the world concerns about thermal comfort, energy savings and 
the search for renewable energy sources. Universities and industries have been working on the development of new materials and technologies on thermal insulation, change-phase materials, cool coatings, selective glasses and passive techniques to promote thermal comfort, which may contribute to attenuate those consequences.

In the last 10 years, Brazil has made efforts to develop regulations for constructions and energy use within this new context. Many sectors are involved in bringing about new habits and strategies for users and designers, as well as testing concepts and ideas developed in others countries and adapting them to local climate conditions. Passive cooling of buildings is not a new concept-several civilizations have applied it in some ancient age. As a result of a long period of observation of climatic events, some civilizations had achieved improvement of thermal conditions in their constructions due to several adaptations. The generalization of their application, however, often implicates in unsatisfactory results. Therefore, these techniques are connected to tradition and culture of a civilization. It was a specific technique useful for the particular location that made buildings peculiar and comfortable. In this context, the aim of this paper is to describe a research where reflective and evaporative cooling systems were applied on a typical house to verify the cooling potentials of roofing in subtropical climate.

\section{Background}

Researches on passive cooling techniques have been developed in many locations with mainly warmer climate. They are showing good results for energy savings in buildings (thermal comfort) and for decreasing the effects of heat islands in cities (urban climate) [1-5]. Materials used in the envelope of buildings (walls and roofing) and the urban structures play a very important role in the urban thermal balance. Those materials absorb solar and infrared radiations, and dissipate part of the accumulated heat, through convective and radiant processes into the atmosphere increasing ambient temperature. Besides that, some of the heat comes into the buildings, thus, increasing the energy consumption for air conditioning in hot climates [6]. Most of the experiments about roofing are located in warm or arid areas. The benefits of cooling roofing in hot and arid locations were also verified in 1996 [4]. The air temperature decreases inside the test structures when compared to the control structure of $7{ }^{\circ} \mathrm{C}, 3{ }^{\circ} \mathrm{C}, 8{ }^{\circ} \mathrm{C}$ and $10{ }^{\circ} \mathrm{C}$ for roofs treated with white paint, underneath thermal insulation, shallow pond with movable thermal insulation and evaporative cooling, respectively. The evaporative cooling performance was the best for these climate conditions, but it required a lot of water, which is scarce in rural arid areas. The evaporative-reflective roof can improve space cooling in buildings. Analysis of results showed, in some cases for hot arid climates, that the most significant factors affecting the cooling powers of the passive cooling roof were the rocks, water volume, aluminium roof thickness and the width of the roof air space.

Generally, less complex climates require specific procedures to obtain a passive cooling. However, in some regions, the climate is mixed as in many tropical locations and it is possible that distinct and different conditions characterize the same season. The solutions to minimize the heat gain through roofing are complex requiring the monitoring of the experiment for more than one season.

The passive cooling of roofing has been tested in warmer climate where the roof is defined as the main responsible for solar heat gain in buildings. Those buildings usually have one pavement or horizontal volume when roof area exposed to solar radiation is larger than walls area. Nevertheless, some methodologies could be applied in other locations where climate analysis is more complex or the experiment could be expensive. Experimental and 
simulation results in France presented an average decrease of $10{ }^{\circ} \mathrm{C}$ in surface temperatures and little differences for the lower temperatures, but a strong impact on the highest temperatures. Even preliminary results show the possibility of application in summer season, however, final results will depend on other factors, such as building characteristics and behaviour of the occupants [7]. In addition, successful experiments were also carried out in moderate climates. Solar reflectance and infrared emittance were applied on roofing in London during the summer. Roof surface temperatures presented an average decrease of $6^{\circ} \mathrm{C}$ during working hours from 07:00 a.m. to 05:00 p.m., and ceiling surface temperatures decreased an average of $3.1{ }^{\circ} \mathrm{C}$ during the same period [8].

Cooling roofing has presented good potential for energy savings, although, with some related problems such as an increase in reflected light, and visual discomfort in the case of no flat roofing [9]. The characteristics of site and buildings, price of energy are other aspects, which could influence and decrease the cooling roofing potential.

Among all reported roof evaporative cooling techniques, roofs covered with wetted bags, roof ponds and wet tissues have been tested in many locations [10-12]. In spite of the benefits presented by these techniques, their use in tropical areas must be very careful because they may increase the proliferation of mosquito larvae and diseases.

\section{Passive Cooling Roofing}

\subsection{Climate Profile}

The research was developed in Campinas, a city located in the State of São Paulo in the southeast region of Brazil. Its climate is classified as subtropical with warm and rainy conditions in summer and drier conditions in mild winter. For better characterization of the research, period data for the frequency of SR (solar radiation), $\mathrm{P}$ (rainfall) and $\mathrm{RH}$ (relative humidity) are shown in Figs. 1-3, respectively. The research period corresponds to early spring when there is a transition from the drier (winter) to the wet season (summer). Temperatures are getting higher and this increase is intensified by the clear sky (few clouds), and higher intensity of SR. It is possible to observe that the critical time is from 11:00 a.m. to before 03:00 p.m. with radiation ranging from 800-1,000 $\mathrm{W} / \mathrm{m}^{2}$.

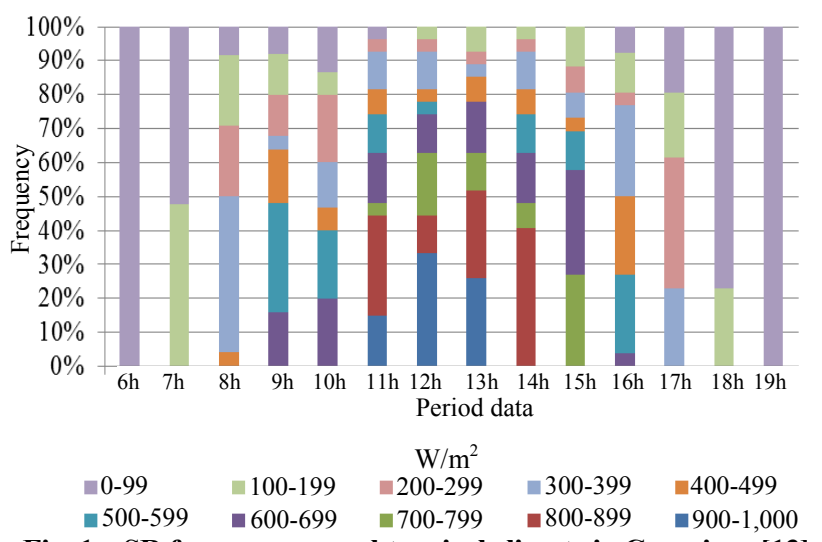

Fig. 1 SR frequency on subtropical climate in Campinas [13].

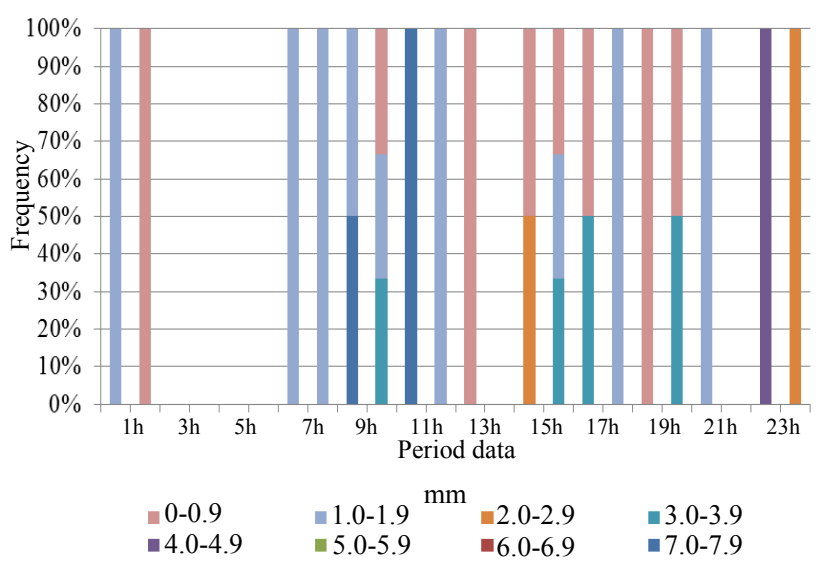

Fig. 2 frequency on subtropical climate in Campinas [13].

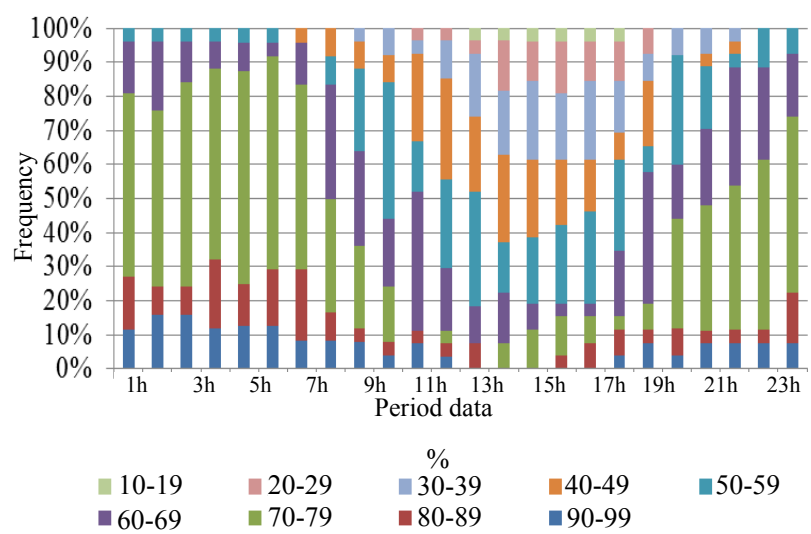

Fig. 3 RH frequency on subtropical climate in Campinas [13]. 
In the beginning of the season, rains are fewer, fast occurring in short time intervals. They are useful in minimizing the effects of the low relative humidity. By noon, more clouds are formed, and the rain becomes more frequent. But toward the end of the season, there are downpours. In some days, it is common to observe $\mathrm{P}$ and direct $\mathrm{SR}$ at the same time. The RH of the air is lower during the day and increases at night. However, during this period, the $\mathrm{RH}$ gradually increases during the summer season when the strong and abundant rain comes.

\subsection{Research Methodology}

The experiment was carried out on the roofing of a single-family house. The monitored roofing is made of fibber cement tiles, it has $2 \%$ inclination and it is located in the frontal part of house, above a garage and a balcony with $11.0 \mathrm{~m} \times 4.5 \mathrm{~m}$ and west orientation. The roof was divided into three parts: two received passive coatings: white impermeable and white acrylic painting and the third part was the reference one with natural tile coating (Fig. 4). Micro water sprayers were fixed on each upper roofing surface, which received painting (Fig. 5).

Climate data were collected each $10 \mathrm{~min}$ from the meteorological station of the IAC (Agronomic Institute of Campinas) [13]. NTC (negative temperature coefficient) surface temperature sensors, with scale from $-25{ }^{\circ} \mathrm{C}$ to $70{ }^{\circ} \mathrm{C}$, were affixed in the underside of the tiles. The sensors were covered with a fixed layer of expanded polystyrene to avoid the influence from outside temperatures. Each sensor was connected to a portable individual mini data logger with precision of $\pm 0.3^{\circ} \mathrm{C}$ (Fig. 6). There is no shading over the roofing from the neighbourhood, mainly in the afternoon. Data were collected at each $10 \mathrm{~min}$.

Otherwise, the literature review presents researches where heat fluxes were monitored. In this case, it was impossible for this first step. Besides that, the house roof structure was from an occupied house allowed for this study. Due to this fact, it was impossible to apply a methodology to monitor air temperature below tiles in different levels.

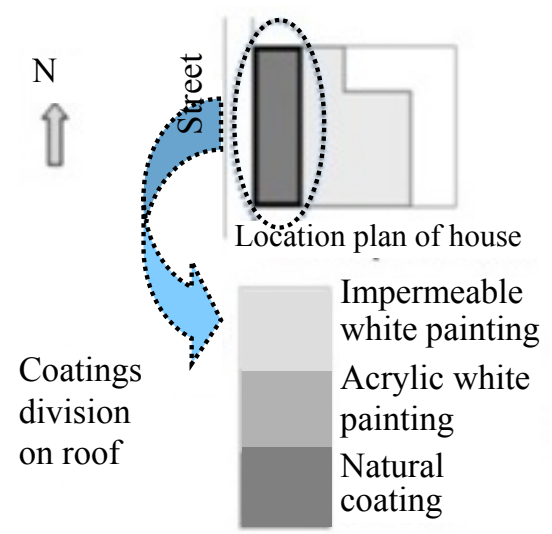

Fig. 4 Roofing plan: localization and roofing areas with reflective coatings.

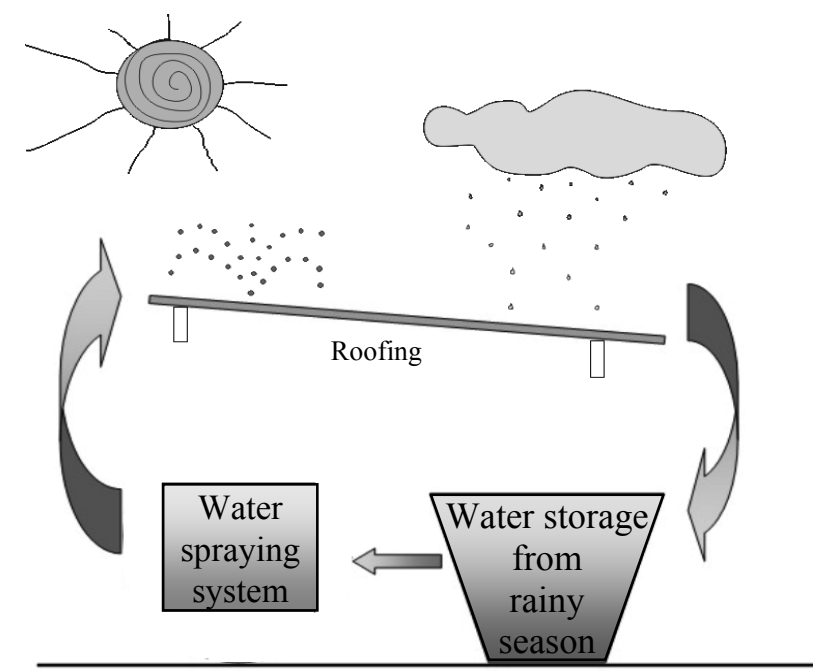

Fig. 5 Evaporative cooling system sketch: from rain-water collection to water spraying on roofing.

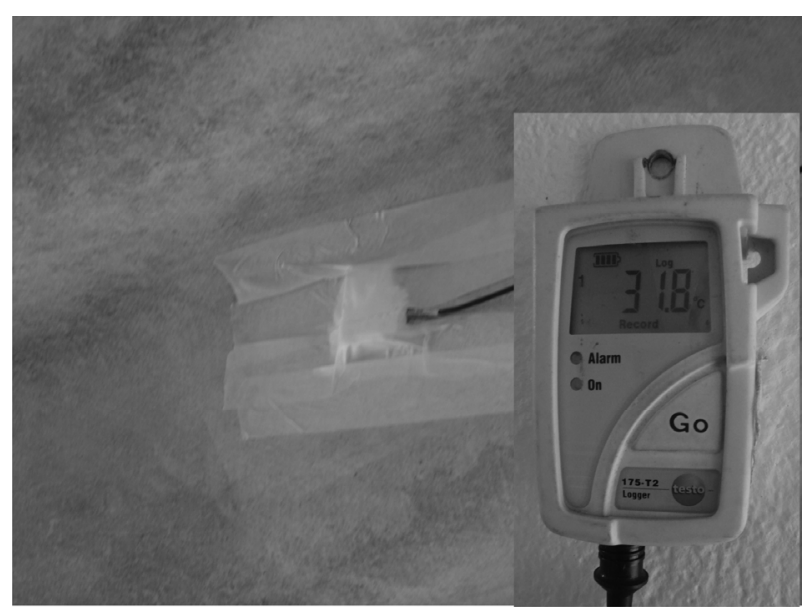

Fig. 6 Surface temperature sensor under the tile (individual sensor and mini logger). 


\section{Results and Discussion}

SR, RH and air temperature (Air T) were collected in order to analyse the following surface temperatures: impermeable white painting on tile (Imp T), acrylic white painting on tile (Acry T) and natural tile (Nat T) in different situations: reflective cooling (Rs), reflective + evaporative cooling ( $\mathrm{R}+$ Es) on sunny days and reflective cooling $(\mathrm{Rr})$ on rainy days. Results are presented in Fig. 7 according to the following criterion: a representative day for each monitored period.

Curves for white coatings show smaller values than natural coating on reflective cooling with sunny days (Rs) (Fig. 8). There is a larger difference among the surface temperatures of white painting tiles and the tiles with natural coating when there is moisture present on the roofing surface. The behaviour can be clearly observed at the points where the evaporative cooling started at 11:00 a.m. and 01:00 p.m. $(\mathrm{R}+\mathrm{Es})$. Even in days with fewer rainy hours, the surface temperature has significant values as compared with the tile exposed to the SR during the whole day (Rr). It is common to have fast and strong rain and solar radiation together at the same time during the day in the Brazilian summer period (Fig. 9).

The RH of the air increased from left to right on Fig. 10. The moisture present on the tile surface in the morning held the temperature rise until 7:00 a.m. when only the Rs was used. The tile surface temperatures, in the others periods ( $\mathrm{R}+\mathrm{Es}$ and $\mathrm{Rr})$, rose late due to the higher levels of moisture on the tile surface in the morning. In relation to the RH of the air, the evaporative cooling worked with the increase of the surface temperature of tile, which happened on hours of higher SR intensity and the consequent lower $\mathrm{RH}$ of the air. Nevertheless, on rainy day and reflective cooling, the RH values were not so low in the middle of the day. Due to the characteristics of the rainy and sunny times throughout the day, when the roofing wet surface turns to receive SR, it tends to delay the increase of surface temperature due to the presence of moisture on the porous tiles.

The percentage of cooling roofing applied on tiles is demonstrated in Fig. 11, where values were calculated in relation to the maximum surface temperature of the natural tile in each period. The acrylic white painting coating presented the best thermal performance during the whole day. It presents

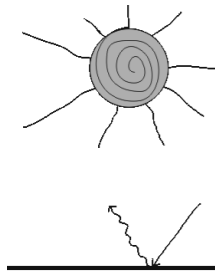

Reflective cooling (Rs)
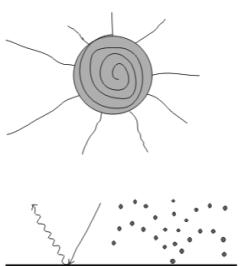

Reflective + evaporative cooling $(\mathrm{R}+\mathrm{Es})$

Sunny days
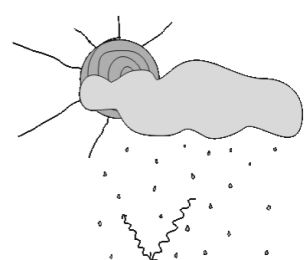

Reflective cooling $(\mathrm{Rr})$
Fig. 7 Evaporative cooling system sketch: rain-water collected and water sprayer on roofing.

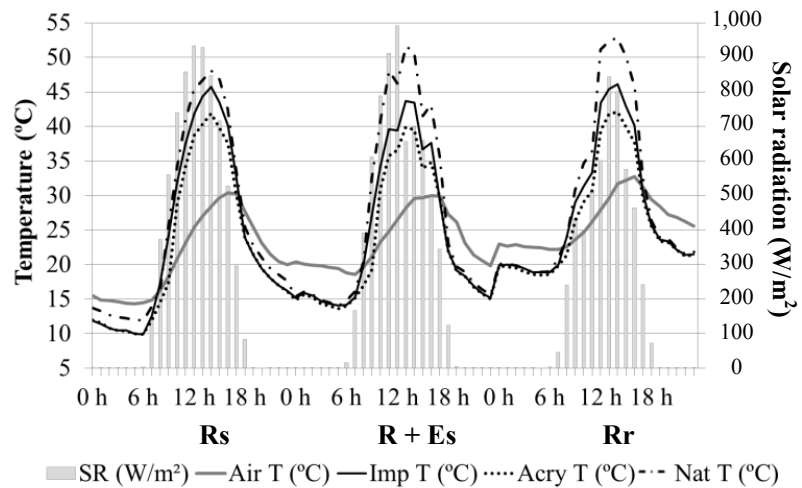

Fig. 8 Surface temperatures $\left({ }^{\circ} \mathrm{C}\right)$ and $\mathrm{SR}\left(\mathrm{W} / \mathrm{m}^{2}\right)$.

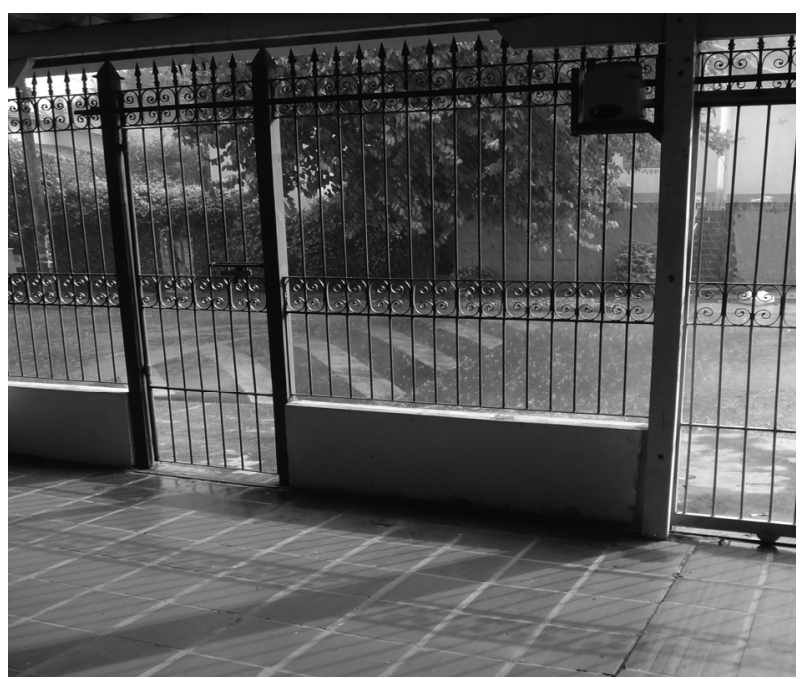

Fig. 9 Rain and solar radiation together in the Brazilian summer day. 


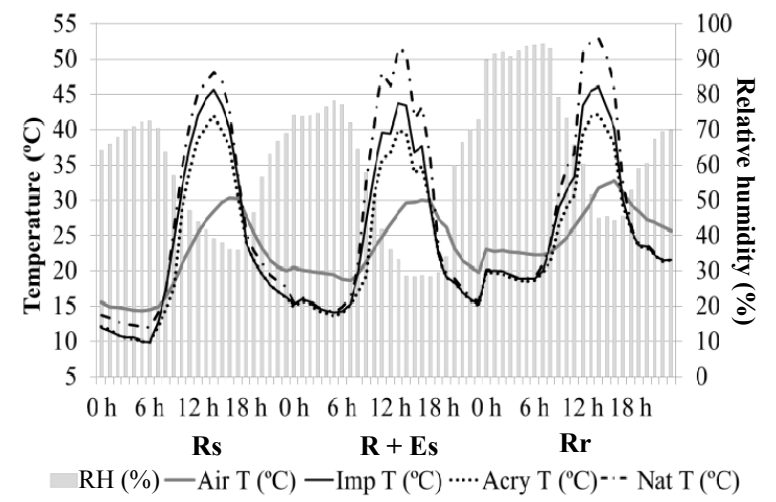

Fig. 10 Surface temperatures $\left({ }^{\circ} \mathrm{C}\right)$ and $\mathrm{RH}(\%)$.

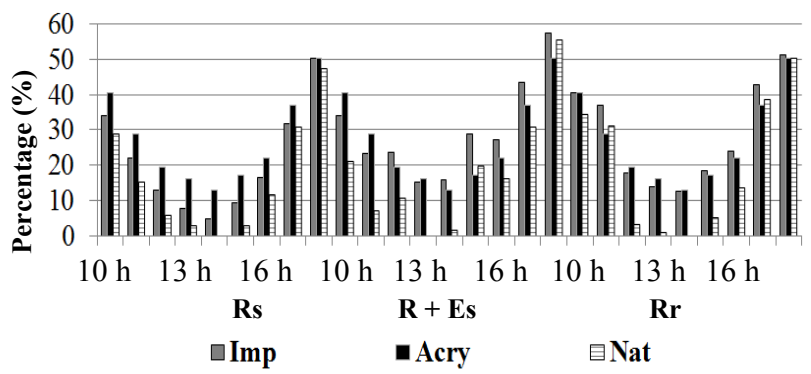

Fig. 11 Percentage of passive cooling roofing: impermeable (Imp) and acrylic (Acry) painting in relation to natural tile (Nat).

$12 \%$ cooling while the impermeable white coating presents $4.9 \%$. In the $(\mathrm{R}+\mathrm{Es})$ period, the SR shows the maximum value at 1:00 p.m. when both white coatings present $16.2 \%$ cooling. Finally, in the last period (Rr), both white coatings present $12.9 \%$ cooling at 2:00 p.m.. There was an alternation in the best performance between the two white coatings in $(\mathrm{R}+\mathrm{Es})$ and the $\mathrm{Rr}$ periods with moisture presence.

\section{Final Considerations}

Several experimental studies about passive cooling of roofing were carried out by the authors since 2005
[14-17]. The experiment described in this work was done in the spring of 2010 under three different environmental conditions (Rs, E $+\mathrm{Rs}$ and Rr). The best values for each period and treatment of tiles in comparison to natural tile are explained in Table 1. There were about $2 \mathrm{~h}$ lag between the maximum values of $\mathrm{SR}$, except $\mathrm{Rr}$ period.

Those values show that the acrylic white painting is better than the impermeable one when the interest is passive cooling of roofing. For the best results, it is possible to combine water spraying together with white coatings for hot and warm conditions in subtropical climate. It means that it is possible to apply only one or the combined techniques in almost all year, mainly in worst climate conditions.

In climatic conditions where the solar radiation is high throughout the year, perhaps the best passive technique will be to shade the building or roofing. It is totally possible for new constructions and architects, and it may help with their ideas and best solutions. The solutions are limited for existing buildings because they require space and different conditions of time when buildings were constructed, for example, reinforcement of structure and new tiles system. The motivation of this research was the fact that cheaper structure and roofing tiles are applied which incite worst thermal conditions. Proposed cheaper solution will be solving this problem immediately. Certainly, it will be necessary to educate people to construct with appropriate materials according to local climate conditions, but this is a long-term solution. White coatings in general have potential for reflective cooling (less solar radiation absorption) and this fact

Table 1 Hourly difference of maximum values of surface temperatures between white coatings and natural tile in each period.

\begin{tabular}{llcc}
\hline & \multicolumn{2}{l}{ Rs } & $\mathrm{E}+\mathrm{Rs}$ \\
\cline { 2 - 3 } & When it was reached maximum values of SR $\left(\mathrm{W} / \mathrm{m}^{2}\right)$ between $12 \mathrm{~h}$ and $13 \mathrm{~h}$ \\
\hline Acry & $6.70^{\circ} \mathrm{C}$ & $9.60{ }^{\circ} \mathrm{C}$ & $10.70{ }^{\circ} \mathrm{C}$ \\
Imp & $3.50{ }^{\circ} \mathrm{C}$ & $6.80{ }^{\circ} \mathrm{C}$ & $6.70{ }^{\circ} \mathrm{C}$ \\
\hline & When it was reached maximum values of Surface Temperatures $\left({ }^{\circ} \mathrm{C}\right)$ at $14 \mathrm{~h}$ \\
\hline Acry & $6.20^{\circ} \mathrm{C}$ & $11.70{ }^{\circ} \mathrm{C}$ & $10.70{ }^{\circ} \mathrm{C}$ \\
Imp & $2.40{ }^{\circ} \mathrm{C}$ & $7.90{ }^{\circ} \mathrm{C}$ & $6.90{ }^{\circ} \mathrm{C}$ \\
\hline
\end{tabular}


makes the whole difference in tropical lands. Of course, there are differences among several kinds of white coatings and they are object of many researches.

The possibility to add water spraying (from rain) so as to obtain better results makes these techniques more interesting. The authors believe that these results were possible only because the experiment was done before the rainy season became stronger. In spite of the fact that the relative humidity was increasing on the last two periods $(\mathrm{R}+\mathrm{Es}$ and $\mathrm{Rr})$, the air saturation did not allow for better results.

\section{Acknowledgments}

The authors wish to thank the FAPESP (Research Founding Agency of São Paulo State), the CNPq (Brazilian Research Council) and the CAPES (Brazilian Coordination for the Education Improvement of Higher Level) for the financial support.

\section{References}

[1] A.H Rosenfeld, H. Akbari, J.J. Romm, M. Pomerantz, Cool communities: Strategies for heat island mitigation and smog reduction, Energy and Buildings 28 (1998) 51-62.

[2] R. Tang, Y. Etzion, I.A. Meir, Estimates of clear night sky emissivity in the Negev Highlands, Israel, Energy Conversion and Management 45 (2004) 1831-1843.

[3] N.M. Nahar, P. Sharma, M.M. Purohit, Studies on solar passive cooling techniques for arid areas, Energy and Buildings 35 (2003) 153-159.

[4] H.B. Cheikh, A. Bouchair, Passive cooling by evapo-reflective roof for hot dry climate, Renewable Energy 29 (2004) 1877-1886.

[5] B. Givoni, Experimental performance of the cooling shower tower in Japan, Energy and Buildings 28 (1998) 25-32.

[6] M. Santamouris, A. Synnefa, T. Karlessi, Using advanced cool materials in the urban built environment to mitigate heat islands and improve thermal comfort conditions, Solar Energy 85 (2011) 3085-3102.

[7] E. Bozonnet, M. Doya, F. Allard, Cool roofs impact on building thermal response: A French case study, Energy and Buildings 43 (2011) 3006-3012.

[8] M. Kolokotroni, B.L. Gowreesunker, R. Giridharan, Cool roof technology in London: An experimental and modelling study, Energy Buildings 1 (2011) 658-667.

[9] H.B. Cheikh, A. Bouchair, Experimental studies of a passive cooling roof in hot arid areas, Revue des Energies Renouvelables 11 (4) (2008) 515-522.

[10] S. Boixo, M. Diaz-Vicente, A. Colmenar, M.A. Castro, Potential energy savings from cool roofs in Spain and Andalusia, Energy 38 (2012) 425-438.

[11] R. Tang, Y. Etzion, Cooling performance of roof ponds with gunny bags floating on water surface as compared with a movable insulation, Renewable Energy 30 (2005) 1373-1385.

[12] R. Tang, E. Etzion, E. Erell, Experimental studies on a novel roof pond configuration for the cooling of building, Renewable Energy 28 (2003) 1513-1522.

[13] IAC-Instituto Agronômico de Campinas, Séries históricas de Campinas (Climate Data Collection of Campinas), Instituto Agronômico, Campinas, 2010.

[14] C.F.B. Teixeira, L.C. Labaki, Study of evaporative cooling roofing in sub-tropical climate, in: 3rd International Conference Passive and Low Energy Cooling for the Built Environment-PALENC, Rhodes Island, 2010.

[15] C.F.B. Teixeira, L.C. Labaki, Evaporative cooling in tropical climate: Case study of Campinas, Brazil, in: Proceedings of 23rd Conference on Passive and Low Energy Architecture-PLEA 2006, 2006, pp. 887-892.

[16] C.F.B. Teixeira, L.C. Labaki, S. Tavares, Studies of thermal behavior of radiant cooling in tropical climate, in: Proceedings of 22nd Conference on Passive and Low Energy Architecture-PLEA 2005, 2005, pp. 407-413.

[17] C.F.B. Teixeira, L.C. Labaki, Study of thermal behaviour of roofing on subtropical climate: The use of radiant barrier, International Journal of Renewable and Sustainable Energy 2 (1) (2013) 12-17. 